\title{
Incidence and risk factors of a severe Clostridium difficile infection: results of a retrospective cohort study at a tertiary care hospital
}

\section{Claas Baier}

Medizinische Hochschule Hannover

Simone Valentin

Stadtspital Triemli

Frank Schwab

Charite Universitatsmedizin Berlin

\section{Sandra Steffens}

Medizinische Hochschule Hannover

\section{Ralf-Peter Vonberg}

Medizinische Hochschule Hannover

Iris Freya Chaberny

Universitatsklinikum Leipzig

Ella Ebadi ( $\sim$ ebadi.ella@mh-hannover.de)

Medizinische Hochschule Hannover

\section{Research article}

Keywords: Clostridium difficile, infection, risk factor, incidence, infection control

Posted Date: August 31st, 2019

DOI: https://doi.org/10.21203/rs.2.13795/v1

License: (c) (1) This work is licensed under a Creative Commons Attribution 4.0 International License. Read Full License 


\section{Abstract}

Background Clostridium difficile infection (CDI) is a relevant healthcare burden worldwide and one of the leading causes for nosocomial diarrhea. Besides mild courses, the development of a severe infection can occur and has a relevant impact on healthcare costs and patient outcome.

Methods We conducted a retrospective cohort study over a 4 year-long period to analyze the incidence of $\mathrm{CDI}$ and the contributing risk factors for a severe course at a tertiary care clinic. Independent risk factors were determined by a multivariable logistic regression analysis.

Results A total of $761 \mathrm{CDI}$ cases were identified in the study period, thereof $612(80.4 \%)$ cases were nosocomially acquired. The mean incidence for a CDI was 0.42 cases per 1000 patient-days. A severe CDI occurred in 131 cases (17.2\%). Independent risk factors for a severe course were pulmonary disease, a Charlson comorbidity index $>3$, and a preceding antibiotic therapy within three months with glycopeptides (vancomycin/teicoplanin) and/or aminoglycosides.

Conclusions This study highlights the relevant burden of CDI in hospitals. Moreover, it underscores that specific knowledge of risk factors contributing to severe CDI is crucial to optimize treatment, infection prevention measures and to guide clinical monitoring and therapy strategy.

\section{Background}

Clostridium difficile (CD) is a Gram-positive, anaerobic bacterium which may produce various toxins and can then cause toxin-related intestinal infections (CD infection; $C D I$ ) [1][2]. The major symptom of CDI is diarrhea. However, severe complications such as fulminant colitis can occur as well. Major risk factors for the onset of $\mathrm{CDI}$ are the application of antibiotics (antibiotic-associated diarrhea) and old age [3][4]. CD spores can persist in the environment for extreme long time periods and, thus, facilitate nosocomial transmission and outbreaks [5][6]. Unfortunately, CDIs have become an increasing clinical and financial burden in healthcare settings all over the world [7][8][9]. Especially severe CDI courses contribute significantly to the morbidity and mortality of affected patients. Thus, knowledge of risk factors for such a severe course of CDI is of high relevance for infection control and prevention efforts as well as practical treatment strategies.

This study therefore provides data on the incidence of severe CDI and contributing risk factors.

\section{Methods}

A 4 year-long retrospective cohort study including all cases with CDI was conducted at the Hannover Medical School, a 1,500-bed tertiary university hospital in northern Germany. The CDI case definition in our study was based on the German surveillance recommendations [10] as follows:

i) Diarrhea or presence of a toxic megacolon together with detection of CD toxins or culture of a toxinproducing $\mathrm{CD}$ strain in stool specimens, or 
ii) Endoscopic diagnosis of pseudomembranous colitis, or

iii) Histopathological diagnosis (e.g. after colectomy or autopsy).

Stool samples were tested for the presence of $C D$ toxins A and/or B using an enzyme-immunoassay (EIA; Ridascreen, r-biopharm, Darmstadt, Germany) in 96-well microtiter plates according to the instructions of the manufacturers within 24 hours after taking the sample. In addition, all stool samples were plated on a prereduced CD selective culture medium (CLO agar, bioMérieux, Nürtingen, Germany) and incubated at $36^{\circ} \mathrm{C}$ for 48 hours under anaerobic conditions. Species of characteristic colonies were further identified by mass spectrometry (matrix assisted laser desorption/ionisation-time of flight; MALDI-TOF; AXIMA Assurance, Kratos Analytical Ltd., Manchester, UK) according to local standard operation protocols. If CD was identified as such, the isolate was then checked for its capability of toxin production by EIA as described above.

A CDI was considered as a severe course if at least one of the following criteria was fulfilled:

i) Admission or re-hospitalization due to recurrent CDI, or

ii) Requirement of intensive care due to CDI or its complications, or

iii) Surgical intervention (e.g., colectomy) due to megacolon, perforation or refractory colitis, or

iv) death within 30 days after CDI diagnosis while CDI was causing or contributing to death [11].

All other cases were considered as a mild course of disease.

CDI was considered nosocomially acquired if:

i) The onset of symptoms occurred $\geq 3$ days after admission, or

ii) The patient had been hospitalized within the last 4 weeks at our facility and CDI was newly diagnosed within the first 2 days following readmission.

Demographic patient characteristics and clinical data (antibiotic therapy, underlying disease, Charlson comorbidity index [12] and length of hospital stay) were collected by examination of medical records. Patients with severe and mild CDIs were compared in a univariable analysis in order to determine relative risks. For the multivariable analysis, a logistic regression analysis with stepwise variable selection forward with the outcome severe CDI was performed. The significance level for entering a variable into the model and for removing a variable from the model was $p<.05$. Statistical analysis was performed using SPSS 25 (IBM SPSS statistics, Somers, NY, USA) and SAS 9.4 (SAS Institute, Cary, NC, USA).

\section{Results}

A total of $761 \mathrm{CDI}$ cases were identified during the study period, thereof $612(80.4 \%)$ were nosocomially acquired cases. The hospital wide incidence for a CDI in the study period was 0.42 cases per 1000 patient days. There were 131 severe CDIs (17.2\%) and $630(82.8 \%)$ mild cases. 
The mean age was 57 years (median 61 years). Mild cases were significantly older than severe cases (58 years vs. 54 years respectively, $p=0.04$ ).

The most common causes for severe CDIs were death within 30 days after CDI diagnosis with CDI contributing $(n=70)$ and the necessity of $(r e)$-admission from recurrent CDI $(n=39)$. Transfer to an intensive care for CDI treatment (including complications) $(n=18)$ and surgical interventions $(n=14)$ occurred less frequently. For severe CDI the hospital wide incidence was 0.07 cases per 1000 patient days. Noteworthy, there was a reduction in the incidence density of severe CDIs from 0.09 cases in the first year to 0.04 cases in the last year of the study period. Mortality was higher in patients with severe CDI cases (71 patients) compared to 19 fatal cases with mild CDI ( $p<0.001)$.

For the risk factor analysis 14 cases were excluded as within 3 days of CD detection another enteral pathogen was found in a stool sample. The results of the univariable risk factor analysis are shown in table 1. In the multivariable analysis, the following parameters were confirmed as independent risk factors for the development of a severe CDI: pulmonary disease, a Charlson comorbidity index $>3$, and a previous antibiotic therapy in the last 3 months with glycopeptides (vancomycin/teicoplanin) or aminoglycosides. Independent protective factors were a heart diseases other than heart insufficiency, a length of hospital stay $>10$ days before the onset of $\mathrm{CDI}$ and the last observation year (table 2).

\section{Discussion}

The incidence of CDI varies to some extent in the literature: A large Czech study reported a mean CDI incidence of 5.2 cases per 10,000 patient days in 27 hospitals in 2015 [13]. Nearly exact the same incidence was reported from an Austrian tertiary care university hospital [14], while a study from France came up with an incidence of only 3.16 cases per 10,000 patient days [15]. A systematic review from Riley and Kimura reports a incidence of $0.8-4.7$ cases per 10,000 patient days in Japanese hospitals [7]. These findings from all over the world are quite in line with the mean incidence in our study and this underscores that CDI is a relevant challenge worldwide. A proportion of $80.4 \%$ of the CDI cases in our cohort were acquired nosocomially which is comparable to other reports, too [15][16][13]. This rather high proportion underlines that $\mathrm{CDI}$ is typically a hospital-associated infection and that nosocomial infection control and prevention efforts deserve high priority. CDI may take a mild clinical course. However, severe infections may occur as well and demand an urgent clinical response. In the medical literature the prevalence of severe CDI ranges from $18.8 \%$ to $57.1 \%$ [17][13][18][16][19].

But one has to keep in mind that these proportions may be based on different definitions of a "severe" CDI. For example, Khanafer et al. showed that the proportion of severe CDI can vary by factor 5 ( $11.6 \%$ vs. $59.2 \%)$ in a patient cohort depending on the "severe" definition applied [15]. The same effect was shown in the study by Starzengruber et al. performed 2014 using either European Society of Clinical Microbiology and Infectious Diseases (ESCMID) or Society of Healthcare Epidemiology of America/Infectious Diseases Society of America (SHEA/IDSA) definitions for severe CDI [14].

Moreover, the definition for a severe CDI has an impact on the results of risk factor assessment [15] and may at least partly explain the heterogeneity in the corresponding data in the literature. In this study we used 
a definition based on the 2006 proposal by the ESCMID Study Group for Clostridium difficile [11]. Advanced age has been found being an independent risk factor for a severe course of CDI by others [18][17], but we failed to confirm these previous findings in our cohort. This was rather unexpected as the definition used by $\mathrm{Na}$ et al. for severe CDI was quite similar to ours and might be due to fact that our patient cohort was rather young ( 57 years mean age) in comparison to the cohort of $\mathrm{Na}$ et al. (67 years mean age). As found by Starzengruber et al. [14] relevant comorbidities (reflected by a Charlson comorbidity index of $>3$ ) were an independent risk factor and therefore should be kept in mind when the risk for the development of a severe course of $\mathrm{CDI}$ is assessed. The same applies to underlying pulmonary diseases as those also increased the risk for severe CDI independently in our cohort as they did in the study of Wenisch et al. in Vienna, Austria [20]. Antibiotic consumption is a well-known major risk factor for CDI development [3][21]. Khanafer et al. reported that fluoroquinolone exposition was associated even with a severe course of CDI [16]. We could also see that antibiotic consumption was independently associated with severe CDI, however this was true only for glycopeptides (vancomycin and teicoplanin) and aminoglycosides. In this context it is important to notice that a history of CDI (which could be a reason for a previous vancomycin therapy) in the previous 12 months was no independent risk factor for a severe course in our cohort (data not shown). Interestingly, deBlank et al. also found aminoglycosides as a risk factor for CDI development in a pediatric oncology [22].

Nevertheless, our multivariable analysis also found protective factors such as a length of hospital stay $>10$ days prior to $\mathrm{CDI}$ onset. This finding is difficult to interpret in a retrospective setting and requires reevaluation in further investigations. We also experienced a constant and significant decrease of severe CDI during the study period. This might be due to an increased awareness leading to enhanced diagnostics and a more appropriate and earlier therapy of $\mathrm{CDI}$, which in consequence might reduce the risk for progress to a severe course.

There are some limitations to our study. First, this was a single center retrospective analysis between 2007 and 2010. Therefore, our findings might not apply completely to other hospitals and settings. Moreover, we might have missed some patients who were not readmitted to our hospital although suffering from recurrent $\mathrm{CDI}$ (recurrent CDI was a criterion for severe CDI). We also did not assess laboratory parameters such as leukocyte count or C-reactive protein for our analysis as other studies did. One general weakness of all studies evaluating the risk factors of severe CDI remains the variation of definitions used which complicates the comparison of results as mentioned above.

\section{Conclusion}

This study showed that CDI (whether mild or severe) represents a relevant nosocomial complication. The knowledge of contributing factors is essential to identify patients at risk for a severe course of CDI in order to optimize the individual treatment strategy and to improve the patient outcome for instance by close clinical monitoring. Therefore, it seems worthy for hospitals to determine risk factors of its specific patient cohort as these may vary between different institutions and depending on the definition used for severe CDI.

\section{List Of Abbreviations}




\section{Declarations}

\section{Ethics approval and consent to participate}

The Protection against Infection Act is the legal basis for the control of infectious diseases in Germany. § 23 of this act demands that hospitals continuously monitor and analyze the occurrence of nosocomial infections. Based on this we collected and accessed data for the study according to data privacy rules. Thus, an approval by the ethic committee was not required.

\section{Consent for publication}

Not applicable (no individual details such as images or videos are included).

\section{Availability of data and materials}

The datasets used and/or analyzed during the current study are available from the corresponding author on reasonable request.

\section{Competing interests}

The authors declare that they have no competing interests

\section{Funding}

This research did not receive any specific grant from funding agencies in the public, commercial, or not-forprofit sectors.

\section{Authors' contributions}

All authors contributed to the manuscript according to the ICMJE (International Committee of Medical Journal Editors) recommendations. EE monitored data acquisition. All authors were involved in data analysis and interpretation. CB, EE and RPV prepared the manuscript. EE organized the drafting process. FS performed statistical analysis. All authors read and approved the final manuscript.

\section{Acknowledgements}

Not applicable. 


\section{Further note}

Preliminary and partial results were presented at the German Society of Hygiene and Microbiology ( $64^{\text {rd }}$ DGHM 2012, 30 September-3 October 2012, Hamburg, Germany, Abstract: PRV02) as oral presentation and are available in an English language abstract in the conference's proceedings.

\section{References}

[1]Balsells E, Shi T, Leese C, Lyell I, Burrows J, Wiuff C, et al. Global burden of Clostridium difficile infections: a systematic review and meta-analysis. J. Glob. Health. 2019;9:010407.

[2]Chandrasekaran R, Lacy DB. The role of toxins in Clostridium difficile infection. FEMS Microbiol. Rev. 2017;41:723-50.

[3]Czepiel J, Dróżdż M, Pituch H, Kuijper EJ, Perucki W, Mielimonka A, et al. Clostridium diffıcile infection: review. Eur. J. Clin. Microbiol. Infect. Dis. 2019;38:1211-21.

[4]Skyum F, Pedersen C, Andersen V, Chen M, Franke A, Petersen D, et al. Risk factors for contagious gastroenteritis in adult patients with diarrhoea in the emergency department - a prospective observational multicentre study. BMC Infect. Dis. 2019;19:133.

[5]Barbut F. How to eradicate Clostridium difficile from the environment. J. Hosp. Infect. 2015;89:287-95.

[6]Graf K, Cohrs A, Gastmeier P, Kola A, Vonberg R-P, Mattner F, et al. An outbreak of Clostridium difficileassociated disease (CDAD) in a German university hospital. Eur. J. Clin. Microbiol. Infect. Dis. 2009;28:5435 .

[7]Riley T V., Kimura T. The Epidemiology of Clostridium difficile Infection in Japan: A Systematic Review. Infect. Dis. Ther. 2018;7:39-70.

[8]Cassini A, Plachouras D, Eckmanns T, Abu Sin M, Blank H-P, Ducomble T, et al. Burden of Six HealthcareAssociated Infections on European Population Health: Estimating Incidence-Based Disability-Adjusted Life Years through a Population Prevalence-Based Modelling Study. PLoS Med. 2016;13:e1002150.

[9]Tresman R, Goldenberg SD. Healthcare resource use and attributable cost of Clostridium difficile infection: a micro-costing analysis comparing first and recurrent episodes. J. Antimicrob. Chemother. 2018;73:28515 .

[10]Gastmeier P, Weitzel-Kage D, Behnke M, Eckmanns T. Surveillance of Clostridium difficile-associated diarrhoea with the German nosocomial infection surveillance system KISS (CDAD-KISS). Int. J. Antimicrob. Agents. 2009;33:S19-23.

[11]Kuijper EJ, Coignard B, Tüll P, ESCMID Study Group for Clostridium difficile, EU Member States, European Centre for Disease Prevention and Control. Emergence of Clostridium difficile-associated disease in North America and Europe. Clin. Microbiol. Infect. 2006;12 Suppl 6:2-18. 
[12]Charlson ME, Pompei P, Ales KL, MacKenzie CR. A new method of classifying prognostic comorbidity in longitudinal studies: development and validation. J. Chronic Dis. 1987;40:373-83.

[13]Krutova M, Matejkova J, Drevinek P, Kuijper EJ, Nyc O, study group. Increasing incidence of Clostridium difficile ribotype 001 associated with severe course of the infection and previous fluoroquinolone use in the Czech Republic, 2015. Eur. J. Clin. Microbiol. Infect. Dis. 2017;36:2251-8.

[14]Starzengruber P, Segagni Lusignani L, Wrba T, Mitteregger D, Indra A, Graninger W, et al. Severe Clostridium difficile infection: Incidence and risk factors at a tertiary care university hospital in Vienna, Austria. Wien. Klin. Wochenschr. 2014;126:427-30.

[15]Khanafer N, Barbut F, Eckert C, Perraud M, Demont C, Luxemburger C, et al. Factors predictive of severe Clostridium difficile infection depend on the definition used. Anaerobe. 2016;37:43-8.

[16]Khanafer N, Touré A, Chambrier C, Cour M, Reverdy M-E, Argaud L, et al. Predictors of Clostridium difficile infection severity in patients hospitalised in medical intensive care. World J. Gastroenterol. 2013;19:803441.

[17] Na X, Martin AJ, Sethi S, Kyne L, Garey KW, Flores SW, et al. A Multi-Center Prospective Derivation and Validation of a Clinical Prediction Tool for Severe Clostridium difficile Infection. Deshpande A, editor. PLoS One. 2015;10:e0123405.

[18]Shivashankar R, Khanna S, Kammer PP, Harmsen WS, Zinsmeister AR, Baddour LM, et al. Clinical factors associated with development of severe-complicated Clostridium difficile infection. Clin. Gastroenterol. Hepatol. 2013;11:1466-71.

[19]Mulki R, Baumann AJ, Alnabelsi T, Sandhu N, Alhamshari Y, Wheeler DS, et al. Body mass index greater than 35 is associated with severe Clostridium difficile infection. Aliment. Pharmacol. Ther. 2017;45:75-81. [20]Wenisch JM, Schmid D, Kuo HW, Simons E, Allerberger F, Michl V, et al. Hospital-acquired Clostridium difficile infection: Determinants for severe disease. Eur. J. Clin. Microbiol. Infect. Dis. 2012;31:1923-30.

[21]Leffler DA, Lamont JT. Clostridium difficile infection. N. Engl. J. Med. 2015;372:1539-48.

[22]de Blank P, Zaoutis T, Fisher B, Troxel A, Kim J, Aplenc R. Trends in Clostridium difficile infection and risk factors for hospital acquisition of Clostridium difficile among children with cancer. J. Pediatr. 2013;163:699-705.e1.

\section{Tables}

Table 1. Basic characteristics of the Clostridium difficile infection (CDI) cases and results of the univariable analysis of factors significantly influencing the risk of severe CDI. 


\begin{tabular}{|c|c|c|c|c|c|c|}
\hline Variable & $\begin{array}{l}\text { \# all } \\
\text { CDI } \\
\text { cases }\end{array}$ & $\begin{array}{l}\text { \# mild } \\
\text { CDI cases } \\
(\%)\end{array}$ & $\begin{array}{l}\text { \# severe } \\
\text { CDI cases } \\
(\%)\end{array}$ & $\mathrm{RR}^{*}$ & CI95\%** & $\begin{array}{l}\text { p- } \\
\text { value*** }\end{array}$ \\
\hline Total & 747 & $617(82.6)$ & $130(17.4)$ & & & \\
\hline \multicolumn{7}{|l|}{ Basic characteristics } \\
\hline Male gender & 406 & $327(80.5)$ & $79(19.5)$ & 1.30 & $\begin{array}{l}0.94- \\
1.79\end{array}$ & 0.12 \\
\hline Age $\leq 54$ years $* * * *$ & 286 & $231(80.8)$ & $55(19.2)$ & 1.18 & $\begin{array}{l}0.86- \\
1.62\end{array}$ & 0.32 \\
\hline \multicolumn{7}{|l|}{ Underlying diseases } \\
\hline Pulmonary diseases & 293 & $229(78.2)$ & $64(21,8)$ & 1.50 & $\begin{array}{l}1.10- \\
2.05\end{array}$ & 0.01 \\
\hline Heart insufficiency & 52 & $36(69.2)$ & $16(30,8)$ & 1.88 & $\begin{array}{l}1.21- \\
2.92\end{array}$ & 0.01 \\
\hline Other heart diseases & 382 & 331 (86.6) & $51(13.4)$ & 0.62 & $\begin{array}{l}0.45- \\
0.85\end{array}$ & $<0.01$ \\
\hline Severe liver disease & 52 & $37(71.2)$ & $15(28.8)$ & 1.74 & $\begin{array}{l}1.10- \\
2.76\end{array}$ & 0.04 \\
\hline $\begin{array}{l}\text { Hematopoietic stem cell } \\
\text { transplantation }\end{array}$ & 29 & $19(65.5)$ & $10(34,5)$ & 2.06 & $\begin{array}{l}1.22- \\
3.50\end{array}$ & 0.02 \\
\hline \multicolumn{7}{|c|}{ Antibiotic treatment within 3 months prior to CDI onset***** } \\
\hline Glycopeptides & 148 & $113(76.4)$ & $35(23,6)$ & 1.49 & $\begin{array}{l}1,06- \\
2,10\end{array}$ & 0.03 \\
\hline Metronidazole & 141 & $106(75.2)$ & $35(24.8)$ & 1.58 & $\begin{array}{l}1.13- \\
2.23\end{array}$ & 0.01 \\
\hline Aminoglycosides & 81 & $58(71.6)$ & $23(28,4)$ & 1.77 & $\begin{array}{l}1.20- \\
2.60\end{array}$ & 0,01 \\
\hline \multicolumn{7}{|l|}{ Others } \\
\hline $\begin{array}{l}\text { Length of hospital stay } \\
>10 \text { days before onset of }\end{array}$ & 356 & $306(86.0)$ & $50(14.0)$ & 0.69 & $\begin{array}{l}0.50- \\
0.95\end{array}$ & 0.03 \\
\hline
\end{tabular}




\begin{tabular}{|l|l|l|l|l|l|l|} 
CDI & & & & & & \\
\hline $\begin{array}{l}\text { Charlson comorbidity } \\
\text { index }>3\end{array}$ & 286 & $222(77.6)$ & $64(22,4)$ & 1.56 & $\begin{array}{l}1.15- \\
2.13\end{array}$ & 0.01 \\
\hline First observation year & 180 & $138(76.7)$ & $42(23,3)$ & 1.50 & $\begin{array}{l}1.08- \\
2.09\end{array}$ & 0,02 \\
\hline Last observation year & 183 & $164(89.6)$ & $19(10.4)$ & 0.53 & $\begin{array}{l}0.33- \\
0.83\end{array}$ & $<0.01$ \\
\hline
\end{tabular}

*Risk ratio. **95\%-confidence interval. ***2-tailed Fisher Exact Test. ****Mean age of the coho with severe CDI. *****Antibiotic treatment that was administered within 4 days just prior to CI confirmation was excluded to minimize bias.

Table 2. Independent factors influencing the risk of severe Clostridium difficile infection (CDI) as determined by multivariable logistic regression analysis

\begin{tabular}{|l|l|l|}
\hline Variable & $\begin{array}{l}\text { OR } \\
* C I 95 \% * *\end{array}$ & $\mathbf{p}$-valu \\
\hline Risk factors & & \\
\hline Pulmonary diseases & $1.651 .10-2.470 .02$ \\
\hline Charlson comorbidity index $>3$ & $1.681 .13-2.510 .01$ \\
\hline Treatment within 3 months prior to CDI onset with glycopeptides & $1.751 .08-2.820 .02$ \\
\hline Treatment within 3 months prior to CDI onset with aminoglycosides & $1.931 .10-3.390 .02$ \\
\hline Protective factors & & \\
\hline Heart diseases other than heart insufficiency & $0.560 .37-0.83<0.01$ \\
\hline Length of hospital stay of $>10$ days before onset of CDI & $0.470 .31-0.72<0.01$ \\
\hline Last observation year & $0.450 .26-0.77<0.01$ \\
\hline
\end{tabular}

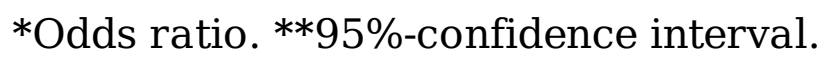

